\title{
Comparison between laser scanning tomography and computerised image analysis of the optic disc
}

\author{
Augusto Azuara-Blanco, George L Spaeth, Jamie Nicholl, Ines M Lanzl, \\ James J Augsburger
}

\begin{abstract}
Aims-To study the interchangeability of the measurements of the optic disc topography obtained by one computerised image analyser and one confocal laser tomographic scanner.

Methods-One eye of 28 patients with glaucoma or glaucoma suspects was studied. All cases had simultaneous stereoscopic disc photographs taken with the fundus camera Topcon TRC-SS and optic disc examination with the Heidelberg retina tomograph (HRT) during the same visit. The optic disc photographs were digitised and analysed with the Topcon ImageNet (TI) system. Three variables of the optic disc topography provided by the TI and the HRT were compared-cup volume (CV), rim area (RA), and cup area to disc area ratio (CA/DA).

Results-The mean values of $\mathrm{CV}$ and RA provided by the TI $(0.52$ (SD 0.32$) \mathrm{mm}^{3}$ and $1.58(0.39) \mathrm{mm}^{2}$, respectively) were greater $(p<0.01)$ than the mean values of CV and RA determined by the HRT $(0.32$ $(0.25) \mathrm{mm}^{3}$, and $1.33(0.47) \mathrm{mm}^{2}$, respectively). The mean value of CA/DA provided by the TI $(0.42(0.14))$ and the HRT $(0.42(0.18))$ was similar $(p=0.93)$. Correlation coefficients between measurements obtained by the two methods ranged from 0.53 to 0.73 .

Conclusion-There was a significant discrepancy in the measurements of rim area and cup volume of the optic disc obtained by a computerised image analyser and a laser scanning tomograph.

(Br f Ophthalmol 1999;83:295-298)
\end{abstract}

Wills Eye Service,

Jefferson Medical

College, Philadelphia,

PA, USA

A Azuara-Blanco

G L Spaeth

J Nicholl

I M Lanzl

Retina Service, Wills Eye Hospital, Jefferson Medical College,

Philadelphia, PA, USA

J J Augsburger

Correspondence to: Augusto Azuara-Blanco, $\mathrm{MD}$, Department of Ophthalmology, B-Floor, South Block, Queen's

Medical Centre, University

Hospital, Nottingham

NG7 2UH.

Accepted for publication 22 September 1998 with different definitions of the margin of the optic disc and cup. For example, image analysers use an optical device to acquire stereopowerful tools in the diagnosis and accurate flow up of patients with glaucoma.

analysers and tomographic sca use different methodologies to determine the

Diagnosis and management of glaucoma regraphy. Computerion of the optic dise toponiques optic nerve head. ${ }^{1-7}$ These high technology subjective evaluation by an examiner than conventional techniques of disc examination. ${ }^{8-12}$ Therefore, theoretically they may be used as and reproducible and more independent of the scopic images of the optic disc, which are then digitised and analysed. ${ }^{12713}$ In contrast, tomographic scanners use a confocal scanning diode laser that changes the focal length to produce an image of the optic nerve head in different planes. ${ }^{3-7}$

Clinical and epidemiological studies using these techniques have been published. ${ }^{1-7}{ }^{15}$ It is not known whether the measurements obtained by image analysers and laser tomographic scanners are interchangeable. Similarity of measurements could allow comparisons between groups of patients, and evaluation of the progression of the disease using different techniques.

The present study was designed to evaluate the interchangeability of the measurements of the optic disc topography obtained by one computerised image analyser, the Topcon ImageNet (TI), and one confocal laser tomographic scanner, the Heidelberg retina tomograph (HRT). Specifically, this study tried to determine the closeness of estimated neuroretinal rim and cup volume values obtained by the TI and the HRT, and the linearity of the relation between the estimates of each variable obtained by these two different methods.

\section{Materials and methods}

The study included 28 patients with glaucoma or glaucoma suspects. The cases were retrospectively selected from the Glaucoma Service at Wills Eye Hospital, Jefferson Medical College. One eye per subject was analysed. When both eyes were available one eye was randomly chosen.

All participants were classified by as "a glaucoma suspect" (intraocular pressure (IOP) greater than $21 \mathrm{~mm} \mathrm{Hg}$ with no other abnormalities, or suspected optic disc damage and no other abnormalities) or "a glaucoma patient" on the basis of IOP measured by Goldmann applanation tonometry, presumed glaucomatous optic disc damage, and visual field loss as determined with the 24-2 threshold program of the Humphrey visual field analyser.

Fifteen women and 13 men, with a mean age of 52.8 (SD 16.1) years, were studied. Twenty three patients were white, four black, and one Asian. Seven patients (25.0\%) were glaucoma suspects and $21(75 \%)$ had glaucoma. The mean spherical equivalent refractive error was -1.2 (SD 1.1) dioptres (range -4 to 0 dioptres).

All cases had simultaneous colour stereoscopic disc photographs taken with the fundus camera Topcon TRC-SS (Topcon Instrument 
Corporation of America, Paramus, NJ, USA) and optic disc examination with the HRT (Heidelberg Engineering, Heidelberg, Germany) during the same visit. The photographic images were acquired after dilatation of the participants' pupil with $1 \%$ tropicamide and $2.5 \%$ phenylephrine.

The optic disc photographs were digitised and analysed with an image analyser system, the Topcon ImageNet (Topcon Instrument Corp of America). Details of this system and the optic disc analysis have been published previously. ${ }^{13-15}$ In brief, the observer marked four points (superior, left, inferior, right) at the optic disc margin. The program automatically fitted an ellipse to the four points, which was considered the optic disc boundary. Using image parallax between corresponding points on the simultaneous stereoscopic image pair, the software program calculated the depth at approximately $400-600$ points within the disc margin. If, owing to poor image quality, the depth at more than $25 \%$ of the points could not be determined, the image analysis data were judged to be unreliable and were excluded from statistical analysis. The cup was automatically demarcated at a depth of $150 \mu \mathrm{m}$ below the margin of the optic disc. The area outlined by the optic disc boundary was the optic disc area $\left(\mathrm{DA}_{\mathrm{TI}}\right)$. The area between the optic disc and optic cup boundary was the neuroretinal rim area $\left(\mathrm{RA}_{\mathrm{TI}}\right)$. The ratio of the rim area to the disc area was the rim to disc ratio $\left(\mathrm{RA} / \mathrm{DA}_{\mathrm{TI}}\right)$. The ratio of the cup area to the disc area $\left(\mathrm{CA} / \mathrm{DA}_{\mathrm{TI}}\right)$ was calculated applying the formula: RA/DA $+\mathrm{CA} / \mathrm{DA}=1$. The volume of the parts $150 \mu \mathrm{m}$ below the optic disc boundary was the cup volume $\left(\mathrm{CV}_{\mathrm{TI}}\right)$. All measurements were corrected for magnification related errors with the use of Littmann's correction factor modified for the simultaneous stereoscopic camera. ${ }^{16}$ The spherical equivalent refractive error for each eye was used to determine this factor. A correction factor using axial length data was not applied because this measurement was not obtained. Each optic disc was analysed once.

The HRT is based on the principle of confocal detection. The instrument has been described. $^{3-7}$ It is a confocal scanning diode $(670 \mathrm{~nm})$ laser ophthalmoscope that obtains topographic images as a series of 32 optical sections at consecutive focal planes. The image consists of $256 \times 256$ pixels, each pixel corresponding to the retinal height at that location. In this study three HRT images were obtained with a 10 degree field of view of each eye. ${ }^{6} \mathrm{~A}$ mean image was created and used in all analyses. The optic disc margin was outlined (along the inner margin of the scleral ring) by a trained operator. The HRT images were acquired and analysed by the same investigator. The optic disc boundary was drawn manually. The reference plane (software 1.11) was located $50 \mu \mathrm{m}$ posterior to the mean height of the disc margin contour line in a temporal segment between 350 and 356 degrees. The height of the standard reference plane is measured relative to the reference ring located along the periphery of the topographic
Table 1 Cup volume $(C V)$, rim area $(R A)$ and cup area to disc area ratio $(C A / D A)$ evaluated by the Heidelberg retina tomograph (HRT) and Topcon ImageNet (TI)

\begin{tabular}{llllllll}
\hline & \multicolumn{2}{l}{ HRT $(n=28)$} & & \multicolumn{2}{l}{ TI $(n=28)$} & \\
\cline { 2 - 3 } & Mean & $S D$ & & Mean & $S D$ & p Value \\
\hline CV $\left(\mathrm{mm}^{3}\right)$ & 0.32 & 0.25 & & 0.52 & 0.32 & $<0.001$ \\
RA $\left(\mathrm{mm}^{2}\right)$ & 1.33 & 0.47 & & 1.58 & 0.39 & 0.004 \\
CA/DA & 0.42 & 0.18 & & 0.42 & 0.14 & 0.93 \\
\hline
\end{tabular}

$\star$ Significance of the differences (paired $t$ test).

image with an outer diameter of $94 \%$ of the total image size and a band width of $3 \%$. The total area within the disc margin was the disc area $\left(\mathrm{DA}_{\mathrm{HRT}}\right)$. The total area of those parts within the disc margin located below the reference plane was the cup area $\left(\mathrm{CA}_{\mathrm{HRT}}\right)$. The total area within the disc margin minus the cup area was the rim area $\left(\mathrm{RA}_{\mathrm{HRT}}\right)$. The ratio of the cup area to the disc area was the cup to disc ratio $\left(\mathrm{CA} / \mathrm{DA}_{\mathrm{HRT}}\right)$. The total volume of those parts within the disc margin located below the reference plane was the cup volume $\left(\mathrm{CV}_{\mathrm{HRT}}\right)$.

The three common variables of the optic disc topography provided by the TI and the HRT were compared-cup volume (CV), rim area (RA), and cup area to disc area ratio (CA/ DA). Paired $t$ test and regression analysis were used to compare the values of those variables provided by scanning laser tomography and computerised image analysis. A $p$ value smaller than 0.05 indicated statistical significance.

\section{Results}

Reliable image analysis was available for all cases. The mean value of $\mathrm{CV}$ provided by the TI (Table 1), 0.52 (SD 0.32) $\mathrm{mm}^{3}$, was greater than the CV value determined by the HRT, $0.32(0.25) \mathrm{mm}^{3}(\mathrm{p}<0.001)$. Mean value of $\mathrm{RA}$ provided by the TI, $1.58(0.39) \mathrm{mm}^{2}$ was greater than the RA value determined by the HRT, $1.33(0.47) \mathrm{mm}^{2}(\mathrm{p}=0.004)$. The mean value of $\mathrm{CA} / \mathrm{DA}$ provided by both systems (Table 1) was similar $(\mathrm{p}=0.93)$. The differences in CV and RA between instruments was similar in emmetropic and myopic subjects.

Figure 1 shows the correspondence between the TI and HRT measurements of the CV. The

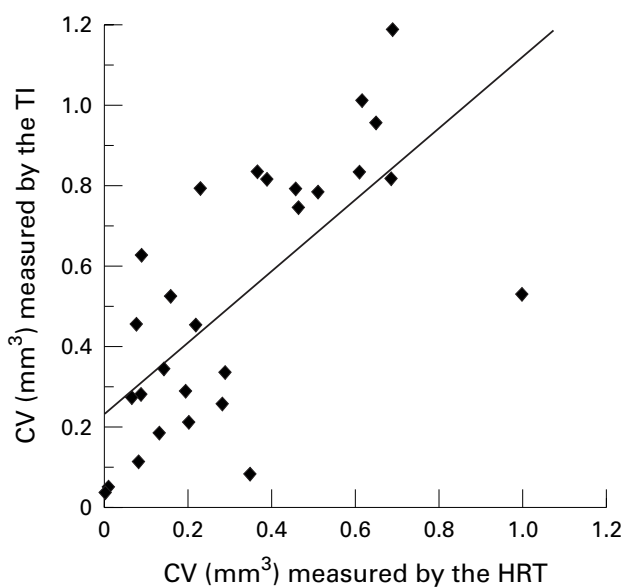

Figure 1 Cup volume (CV) measured by Topcon ImageNet, TI, (y axis) and the Heidelberg retina tomograph, HRT (x axis). Scatter plot and linear regression analysis. 


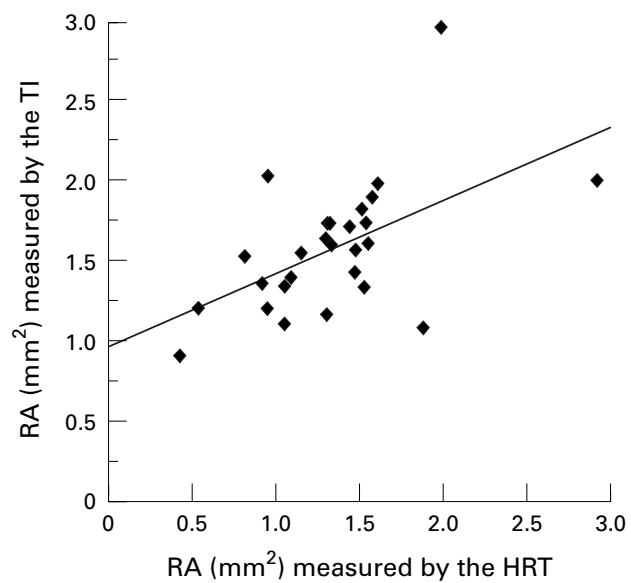

Figure 2 Rim area (RA) measured by Topcon ImageNet, TI, (y axis) and the Heidelberg retina tomograph, HRT ( $x$ axis). Scatter plot and linear regression analysis.

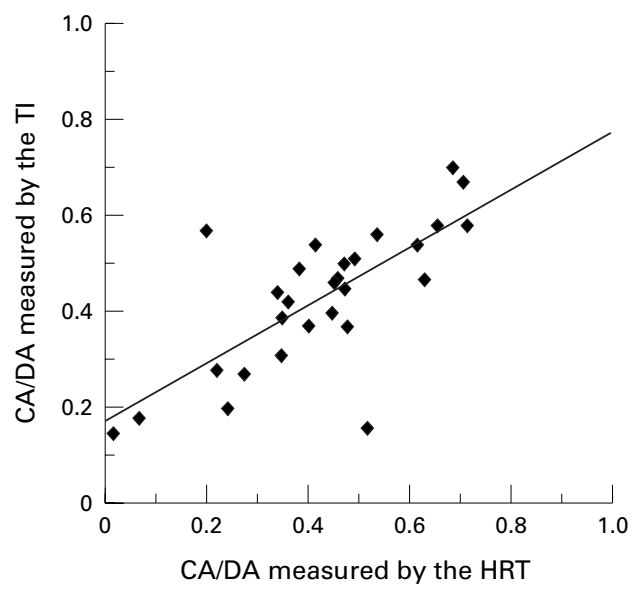

Figure 3 Cup area to disc area ratio $(C A / D A)$ measured by Topcon ImageNet, TI, (y axis) and the Heidelberg retina tomograph, HRT ( $x$ axis). Scatter plot and linear regression analysis.

correlation coefficient was 0.69. In Figure 2 a comparison of measurements of RA provided by both systems is given. The correlation coefficient was 0.53 . Figure 3 shows the relation between TI and HRT measurements of CA/DA, with $r=0.73$.

\section{Discussion}

Previous studies found good correlation between video ophthalmography or computerised image analysis and clinical planimetry. ${ }^{14} 1718$ Dichtl et al recently reported that the HRT measurements of the rim area were significantly larger than the values provided by planimetry. ${ }^{18}$ The present study compares measurements of topographical variables obtained by image analysis and laser scanning tomography. Overall, there was not a strong relation in the measurements of cup volume and neuroretinal rim area between scanning laser tomography values and computerised image analysis.

In theory, the discrepancy between TI and HRT in rim area and cup volume can be due to the variability of the measurements or to differences between systems in the correction of magnification, delimitation of the optic disc boundary, definition of cup border variables, and determination of the reference plane. It is unlikely that reproducibility limitations are the reason for these results since the reproducibility of the TI and HRT measurements has been shown to be adequate. ${ }^{1-7}$ However, in this study the variability of the measurements was not evaluated, and it is possible that the correlation among these instruments might have been different if multiple measurements were obtained with both instruments. ${ }^{6}{ }^{19}$ Magnification errors and methodological differences between TI and HRT (in the delimitation of the optic disc margin, the outer edge of the cup, and the reference plane) must be considered as the most likely contributors to the discrepancies observed in this study. For example, in the TI the cup was demarcated at a depth of $150 \mu \mathrm{m}$ below the margin of the optic disc while in the HRT the cup included those parts located below a retinal reference plane.

This study was not designed to determine which technique is most accurate or best correlates with clinical estimation of disc topography. Considering the differences of rim and cup measurements further studies are needed to compare the accuracy of both techniques. This study is limited by the population studied, which may not be representative of the total population of glaucoma patients or glaucoma suspects. It is possible that magnification corrections could improve the agreement between instruments in absolute measurements (that is, RA and $\mathrm{CV}$ ) ${ }^{20}$; the ratio CA/DA is not affected by this factor.

In conclusion, comparison of characteristics of optic disc of populations evaluated with different techniques (that is, computerised image analysis and laser scanning tomography) should be made with caution. In the follow up of glaucoma patients it would be prudent to use a single technique for repeated measures of rim area or cup volume.

The authors thank Dr Tarek Eid for his assistance.

1 Varma R, Steinmann WC, Spaeth GL, et al. Variability in digital analysis of optic disc topography. Graefes Arch Clin Exp Ophthalmol 1988;226:435-42.

2 Dandona L, Quigley HA, Jampel HD. Variability of depth measurements of the optic nerve head and peripapillary retina with computerized image analysis. Arch Ophthalmol 1989;107:1786-92.

3 Dreher AW, Tso PC, Weinreb RN. Reproducibility of topographic measurements of the normal and glaucomatous optic nerve head with the laser tomographic scanner. $A m \mathcal{F}$ Ophthalmol 1991;111:221-9.

4 Burk ROW, Rohrschneider K, Takamoto T, et al. Laser scanning tomography and stereophotogrammetry in threedimensional optic disc analysis. Graefes Arch Clin Exp 1993;231:193-8.

5 Cioffi GA, Robin AL, Eastman RD, et al. Confocal laser scanning ophthalmoscope. Reproducibility of optic nerve head topographic measurements with the confocal laser scanning ophthalmoscope. Ophthalmology 1993;100:5762 .

6 Weinreb RN, Flower RW, Addicks EM, et al. Effect of repetitive imaging on topographic measurements of the optic nerve head. Arch Ophthalmol 1993;111:636-8.

7 Azuara-Blanco A, Harris A, Cantor LB. Reproducibility of optic disc topographic measurements with the Topcon ImageNet and the Heidelberg Retina Tomograph. Ophthalmologica 1998;212:95-8.

8 Lichter PR. Variability of expert observers in evaluating optic disc. Trans Am Ophthalmol Soc 1976;74:532-72.

9 Sommer A, Pollack I, Maumenee E. Optic disc parameters and onset of glaucomatous field loss. I. Methods and progressive changes in disc morphology. Arch Ophthalmol progressive chang

10 Tielsch JM, Katz J, Quigley HA, et al. Intraobserver and interobserver agreement in measurement of optic disc characteristics. Ophthalmology 1988;95:350-6. 
11 Varma R, Spaeth GL, Steinmann WC, et al. Agreement between clinicians and an image analyzer in estimating

12 Coleman AL, Sommer A, Enger C, et al. Interobserver and intraobserver variability in the detection of glaucomatous progression of the optic disc. F Glaucoma 1996;5:384-9.

13 Varma R, Spaeth GL. The PAR IS 2000 - a new system fo retinal digital analysis. Ophthalmic Surg 1988;19:183-92.

14 Varma R, Douglas GR, Steinmann WC, W et al. A comparative evaluation of three methods of analyzing optic disc topography. Ophthalmic Surg 1989;20:813-9.

15 Varma R, Tielsch JM, Quigley HA, et al. Race-, age-, gender-, and refractive error-related differences in the normal optic disc. Arch Ophthalmol 1994;112:1068-75.

16 Littmann H. Zur Bestimmung der wahren Große eines Objektes auf dem Hintergrund des lebenden Auges. Klin Monatsbl Augenheilkd 1982;180:286-9.
17 Mikelberg FS, Douglas GR, Schulzer M, et al. The correlation between cup-disk ratio, neuroretinal rim area, and optic disc area measured by the video-ophthalmograph Rodenstock analyzer) and clinical measurements. Am $\mathcal{f}$ Ophthalmol 1986;101:7-12.

18 Dichtl A, Jonas JB, Mardin CY. Comparison between tomographic scanning evaluation and photographic measurement of the neuroretinal rim. Am f Ophthalmol 1996;121: 494-501.

19 Burgoyne CF, Quigley HA, Varma RV. Comparison of clinician judgement with digitized image analysis in the detection of induced optic disk change in monkey eyes. $\mathrm{Am}$ f Ophthalmol 1995;120:176-83.

20 Bengtsson B, Krakau CET. Correction of optic disc measurements on fundus photographs. Graefes Arch Clin Exp Ophthalmol 1992;230:24-8. 